\title{
POTENSI KANDUNGAN UNSUR KIMIA EKONOMIS PADA LARUTAN PANAS BUMI DENGAN STUDI KASUS DI PLTP DIENG, KABUPATEN WONOSOBO DAN KABUPATEN BANJARNEGARA, PROVINSI JAWA TENGAH
}

\section{THE POTENTIAL CONTENT OF ECONOMIC CHEMICALS ELEMENT IN GEOTHERMAL SOLUTIONS WITH A CASE STUDY IN THE DIENG GEOTHERMAL POWER PLANT, WONOSOBO REGENCY AND BANJARNEGARA REGENCY, CENTRAL JAVA PROVINCE}

\author{
Sabtanto Joko Suprapto1, Suparno ${ }^{1}$, dan Umi Yuliatin² \\ ${ }^{1}$ Politeknik Energi dan Pertambangan Bandung \\ ${ }^{2}$ Politeknik Energi dan Mineral Akamigas \\ sabtanto.js@esdm.go.id
}

\section{ABSTRAK}

Fluida panas bumi mempunyai kandungan unsur terlarut yang sangat tinggi. Metode geokimia digunakan untuk mengetahui indikasi potensi unsur kimia ekonomis yang terlarut. Eksplorasi panas bumi telah dilakukan di seluruh wilayah Indonesia terutama oleh Badan Geologi, menghasilkan data geokimia dari mata air panas, dengan menganalisis $\mathrm{SiO}_{2}, \mathrm{Al}, \mathrm{Fe}, \mathrm{Ca}, \mathrm{Mg}$, $\mathrm{Na}, \mathrm{K}, \mathrm{Li}, \mathrm{As}, \mathrm{NH}_{4}, \mathrm{~B}, \mathrm{~F}, \mathrm{Cl}, \mathrm{SO}_{4}, \mathrm{HCO}_{3}$, dan $\mathrm{CO}_{2}$. Berdasarkan hasil kompilasi data geokimia dari 256 titik lokasi mata air panas di Indonesia, diolah secara statistik untuk mengetahui tipe fluida yang mempunyai potensi unsur terlarut tinggi serta, kelompok asosiasi unsur. Pembangkit Listrik Tenaga Panas Bumi (PLTP) Dieng dengan permasalahan terbentuknya kerak silika, menarik untuk studi kasus potensi unsur ekonomis yang terlarut. Peninggian kandungan terlarut pada fluida panas bumi selain terbentuk secara alami, dipicu lebih kuat lagi oleh sistem operasi pembangkit panas bumi, yang mengubah fasa cair menjadi fasa uap, sehingga fasa cair yang tersisa menjadi semakin pekat. Potensi kandungan unsur kimia ekonomis ditentukan dengan pengukuran debit fasa cair terproduksi yang tersisa dan hasil analisis konsentrasi unsur terlarutnya. Hasil clustering data geokimia mata air panas diperoleh empat kelompok asosiasi unsur, kelompok $\mathrm{SiO}_{2}-\mathrm{F}, \mathrm{Al}-\mathrm{Fe}-\mathrm{SO}_{4}, \mathrm{Ca}-\mathrm{Mg}-\mathrm{Cl}-\mathrm{Na}-\mathrm{K}$, dan kelompok $\mathrm{Li}-\mathrm{B}-\mathrm{HCO}_{3}$. Kandungan litium terlarut tinggi di beberapa daerah panas bumi di Indonesia, terdapat pada mata air panas dengan fluida tipe khlorida. Brine terproduksi dari reservoir di PLTP Dieng berasal dari fluida tipe meteorik yang telah intensif bereaksi dengan batuan sekitar dan fluida tipe magmatik. Brine tersisa yang berasal dari beberapa separator dan keluar melewati silencer, di PLTP Dieng, mempunyai total debit $457,1 \mathrm{~m}^{3} / \mathrm{jam}$, dengan kandungan kadar tinggi beberapa unsur kimia, litium 77,31-99,4 mg/l, silika 1109,25-1220,9 mg/l, boron 404,16-589,4 mg/l, kalium 2532,2-4536,5 mg/l, dan mangan 5,49-15,82 mg/l.

Kata kunci: Potensi, unsur kimia ekonomis, panas bumi, Dieng

\section{ABSTRACT}

The Geothermal fluid has a very high content of dissolved elements. Geochemical methods are used to determine the potential indication of dissolved economic elements. Geothermal exploration has been carried out throughout Indonesia, mainly by the Geological Agency. The exploration result in the existence of hot spring data by analyzing $\mathrm{SiO}_{2}, \mathrm{Al}, \mathrm{Fe}, \mathrm{Ca}, \mathrm{Mg}, \mathrm{Na}, \mathrm{K}$, $\mathrm{Li}, \mathrm{As}, \mathrm{NH}_{4}, \mathrm{~B}, \mathrm{~F}, \mathrm{Cl}, \mathrm{SO}_{4}, \mathrm{HCO}_{3}$, and $\mathrm{CO}_{2}$. Base on the secondary data of 256 locations of hot spring in Indonesia that were statistically analyzed, an overview of the association of economic elements and impurities elements is obtained. Dieng Geothermal Power Plant with that has recuring problem of silica scale formation, becomes an interesting object as a case study of the potential of dissolved economic elements. The increase in dissolved content in geothermal fluids apart from naturally occurring, is triggered even more strongly by the geothermal power 
plant operating system, which changes the liquid phase to the vapor phase, hence the remaining liquid phase more concentrated. The potential content of economic chemical elements is determined by discharge measuring of the remaining liquid phase produced and the results of the analysis of the element concentration dissolved. The results of geochemical data clustering of hot springs obtained four elemental association, the association of $\mathrm{SiO}_{2}-\mathrm{F}$, $\mathrm{Al}-\mathrm{Fe}-\mathrm{SO}_{4}, \mathrm{Ca}-\mathrm{Mg}-\mathrm{Cl}-\mathrm{Na}-\mathrm{K}$, and $\mathrm{Li}-\mathrm{B}-\mathrm{HCO}_{3}$. Dissolved lithium content is high in several geothermal areas in Indonesia, found in hot springs with chloride type fluids. The brine produced from the reservoir at the Dieng Geothermal Power Plant is from a meteoric type fluid that has intensively reacted with the surrounding rock and a magmatic type fluid. The remaining brine that is from several separators and comes out through the silencer, at the Dieng Geothermal Power Plant has a total discharge of $457.1 \mathrm{~m}^{3} /$ hour, contains high levels of several elements, lithium 77.31-99.4 mg/l, silica 1109.25-1220.9 mg/l, boron 404.16-589.4 mg/l, potassium 2532.2-4536.5 mg/l, and manganese 5.49-15.82 $\mathrm{mg} / \mathrm{l}$.

\section{Keywords: Potency, economic chemicals element, geothermal, Dieng}

\section{PENDAHULUAN}

\section{Latar Belakang}

Pemanfaatan energi panas bumi untuk membangkitkan listrik melibatkan produksi fluida dalam jumlah sangat besar. Indonesia selain diapit di antara tiga lempeng besar, Lempeng India-Australia, Lempeng Pasifik, dan Lempeng Eurasia, juga dibangun oleh sekitar 20 lempeng mikro (Metcalfe, 2017), yang menghasilkan tataan geologi sangat komplek, potensi sumber daya geologi, termasuk panas bumi merata hampir di seluruh wilayah Indonesia. Potensi panas bumi tidak hanya untuk energi, akan tetapi pada fluidanya mengandung unsur-unsur terlarut yang potensial dapat diekstraksi menghasilkan bahan ekonomis. Di beberapa negara, fluida panas bumi mempunyai kandungan mineral terlarut sangat tinggi dan potensial bernilai ekonomi. Sebelum diinjeksikan kembali ke dalam bumi kandungan terlarut dapat terlebih dahulu diekstraksi (Patterson, 2006). Batasan nilai kandungan unsur kimia terlarut untuk dapat diklasifikasikan ekonomis bersifat dinamis, tergantung pada kondisi pasar (Bakane, 2013).

Unsur terlarut pada fluida panas bumi di antaranya yaitu $\mathrm{SiO}_{2}, \mathrm{Al}, \mathrm{Fe}, \mathrm{Ca}, \mathrm{Mg}, \mathrm{Na}, \mathrm{K}$, $\mathrm{Li}$, As, $\mathrm{NH}_{4}, \mathrm{~B}, \mathrm{~F}, \mathrm{Cl}, \mathrm{SO}_{4}, \mathrm{HCO}_{3}, \mathrm{CO}_{2}$. Analisis terhadap kandungan unsur-unsur tersebut selalu dilakukan pada tahapan eksplorasi, terutama sampel dari manifestasi panas bumi berupa mata air panas. Unsur terlarut kadar lebih tinggi dapat dijumpai pada fluida/brine yang berasal dari separator, hal ini mengingat sebagian brine terpisah menjadi uap untuk memutar turbin, sehingga brine sebagai fasa cair yang tersisa menjadi lebih pekat.

\section{Maksud dan Tujuan}

Di PLTP Dieng, silika terlarut pada brine sangat tinggi. Untuk menangani tingginya kandungan silika, brine dilewatkan pada kolam pengendap silika, sebelum diinjeksikan kembali ke dalam bumi (Pohan dkk., 2008). Sehingga sistem pembangkit tersebut dapat memberikan peluang untuk memanfaatkan unsur ekonomi terlarut, baik silikanya maupun unsur-unsur kimia ekonomi lain dari brine yang berada pada kolam pengendapan.

Penelitian ini untuk mengetahui tipe fluida dari mata air panas di Indonesia yang mempunyai potensi unsur kimia ekonomis terlarut tinggi, serta kelompok asosiasi unsur. Studi kasus di PLTP Dieng, dengan tujuan untuk mendapatkan potensi jumlah brine tersisa yang diinjeksikan kembali ke dalam bumi serta kandungan unsur kimia ekonomis terlarutnya.

\section{Tinjauan Pustaka}

Definisi sesuai dengan Undang-undang nomor 21 Tahun 2014 tentang Panas Bumi, yaitu panas bumi merupakan sumber energi panas yang terkandung di dalam air panas, uap air dan batuan, yang keberadaannya bersama mineral ikutan 
dan gas lainnya dalam satu sistem yang secara keterjadiannya tidak bisa saling dipisahkan. Mineral ikutan yang terkandung dalam fluida panas bumi berpotensi untuk dimanfaatkan, sehingga dapat menambah nilai keekonomian dari energi panas bumi.

Asal dari fluida panas bumi dijelaskan oleh Nicholson (1993) dapat bersumber dari magma (juvenile waters), air connate atau air formasi, air metamorfik, dan air meteorik. Larutan hidrotermal terpanaskan pada kedalaman bumi dalam kurun waktu yang lama, terus menerus berkonveksi, bersentuhan dan berinteraksi dengan batuan sekitarnya yang dilewati, menyebabkan terlarutnya mineral-mineral dan kandungan logam dari batuan.

Selain dipengaruhi asal fluida, komposisi fluida juga dipengaruhi oleh jenis magma, komposisi batuan yang mengalami interaksi dengan fluida, $\mathrm{pH}$, adanya zona pendidihan (boiling), serta dipengaruhi temperatur. Semakin tinggi temperatur semakin tinggi unsur yang dapat terlarut (Bloomquist, 2006).

Fluida pada temperatur permukaan mempunyai salinitas atau TDS kurang dari 1000 (ppm), pada temperatur tinggi salinitas dapat lebih dari 300.000 ppm (Entingh dan Vimmerstedt, 2005 dalam Blommquist, 2006). Hickson dan Coolbaugh (2017) menyebutkan bahwa peningkatan temperatur sangat signifikan meningkatkan kandungan litium terlarut pada hidrotermal. Demikian juga berdasarkan metode geotermometri $\mathrm{Na} / \mathrm{Li}$ Sanjuan dan Millot (2009) untuk estimasi temperatur reservoir, semakin tinggi kandungan $\mathrm{Li}$ akan semakin tinggi temperatur reservoir panas bumi.

Total konsentrasi garam pada hidrotermal sesuai dengan nilai densitas. Konsentrasi khlorida cenderung merefleksikan variasi kandungan penyusun dari larutan. Kandungan unsur dalam fluida dapat mengindikasikan lingkungan geologi. Sebagai contoh kandungan fluida kaya akan litium, sesium dan rubidium berasal dari lingkungan batuan kaya silika (Bourcier dkk., 2005).

Fluida panas bumi dapat diekstraksi untuk mendapatkan kandungan mineral atau unsur ekonominya. Teknik pemisahan dan pemurnian dikenal dengan teknik metalurgi hidrotermal. Sehingga pengolahan mineral dari larutan panas bumi dapat memberikan pendapatan tambahan dari pemanfaatan energi panas bumi (Glassley, 2015).

Ekstraksi fluida panas bumi potensial dapat menghasilkan beberapa jenis komoditas, yaitu logam mulia, grup platinum, seng, timbal, tembaga, mangan, REE, silika, litium, arsen, antimoni, boron, bromida, yodium, stronsium, barium sulfat, kalsium khlorida, garam dapur, sodium sulfat dll. (Gallup, 1998; Harper dkk., 1992 dalam Bourcier dkk., 2005). Tinggi rendahnya serta variasi komposisi penyusun fluida tersebut dipengaruhi sistem panas bumi dan tataan geologi setempat.

Volume fluida yang teralirkan dalam satu hari pada pembangkit listrik tenaga panas bumi sangat besar sehingga meskipun kandungan unsur terlarut rendah, sangat memungkinkan menghasilkan dalam jumlah yang ekonomis (Bloomquist, 2006 dalam Kruger, 2015). Hasil sampingan berupa mineral atau logam memberikan pendapatan tambahan sehingga menambah tingkat keekonomian PLTP (Kruger, 2015).

Meskipun kandungan unsur ekonomis pada fluida panas bumi relatif rendah dibandingkan dengan hasil pelarutan pada proses hidrometalurgi bijih logam dari lokasi tambang, akan tetapi beaya ekstraksi dari fluida panas bumi relatif jauh lebih rendah. Hal ini mengingat beberapa faktor sebagai berikut:

- Operasional pabrik pengolahan fluida merupakan gabungan dengan operasional pembangkit. Instalasi dan proses ekstraksi logam/mineral hanya merupakan tambahan dari rangkaian kegiatan PLTP.

- Tidak memerlukan proses penambangan dan proses fisik seperti 
pada ekstraksi deposit bijih, sehingga dampak terhadap lingkungan sangat kecil dibandingkan kegiatan tambang mineral.

- Bahan sudah berupa larutan, sehingga tidak ada tahapan proses pelarutan logam sebagaimana proses pelarutan dari bijih.

- Meskipun kandungan logam pada fluida panas bumi rendah, akan tetapi volume fluida yang diproses jumlahnya sangat besar, bisa mencapai puluhan juta liter/hari, sehingga jumlah unsur berharga yang dapat diambil dalam sekala ekonomi sangat signifikan (Bourcier dkk., 2005).

Mroczek, dkk., (2015), melakukan penelitian ekstraksi litium di geotermal Wairakei, dengan kandungan maksimum $\mathrm{Li}$ $13 \mathrm{mg} / \mathrm{ltr}$, termasuk tinggi apabila dibandingkan dengan kandungan $\mathrm{Li}$ di lokasi geotermal yang lain di New Zealand. Demikian juga hasil asesmen brine geotermal di Amerika oleh Neupane dan Wendt (2017) mengklasifikasikan kadar tinggi dan potensial untuk diekstraksi pada kandungan litium $>20 \mathrm{mg} / \mathrm{l}$.

Penelitian pada lapangan panas bumi di Dieng dengan melakukan pengambilan sampel endapan silika pernah dilakukan Kelompok Program Penelitian Konservasi, Pusat Sumber Daya Geologi, Badan Geologi, pada bulan April 2008 (Pohan, dkk, 2008), sampel yang diambil endapan silika. Hasil analisis kandungan logam pada silika didapatkan kadar yang signifikan beberapa unsur logam. Dari tujuh sampel endapan silika, diperoleh kadar rata-rata: Au 0,477 ppm, perak 3,14 ppm, $\mathrm{Hg}$ 1,982 ppm, As 69,14 ppm, Sb 46,14 ppm, Pb 115,43 ppm, dan As 199 ppm.

\section{METODOLOGI}

Data sekunder didapatkan dari kompilasi hasil penelitian geokimia panas bumi yang dilaksanakan pada kurun waktu 2008 sampai dengan 2015, terutama oleh Badan Geologi, dengan lokasi seluruh Indonesia, sampel geokimia berupa air dari mata air panas. Pengambilan air panas dilakukan pada tempat di mana temperatur dan debitnya paling tinggi, agar kontaminasi oleh lingkungannya dapat dihindari seminimal mungkin. Peralatan pengambilan sampel terdiri-dari botol poliethylene kapasitas $500 \mathrm{ml}$ yang tahan terhadap asam, panas dan korosif; syringe plastik tahan panas kapasitas minimal 50 $\mathrm{ml}$; altimeter, stop watch, $\mathrm{pH}$ meter digital, kertas $\mathrm{pH}$, konduktivitimeter dan $\mathrm{HNO} 31$ : 1 (Wibowo dan Kusnadi, 2015).

Data sekunder dari lapangan panas bumi seluruh Indonesia tersebut, selanjutnya dilakukan pengolahan statistik untuk mendapatkan korelasi antar unsur, kelompok (cluster) unsur, serta mendapatkan harga peninggian kandungan unsur yang mencerminkan lapangan panas bumi berpotensi mengandung unsur ekonomis. Data kandungan unsur kimia yang dikompilasi, di antaranya $\mathrm{SiO}_{2}, \mathrm{Al}, \mathrm{Fe}, \mathrm{Ca}, \mathrm{Mg}, \mathrm{Na}, \mathrm{K}, \mathrm{Li}$, As, $\mathrm{NH}_{4}, \mathrm{~B}, \mathrm{~F}, \mathrm{Cl}, \mathrm{SO}_{4}, \mathrm{HCO}_{3}$, dan $\mathrm{CO}_{2}$. Hasil analasis statistik dari data tersebut diharapkan dapat menggambarkan secara umum geokimia panas Indonesia. Tidak semua unsur masing-masing akan dibahas lebih lanjut, akan tetapi berdasarkan analisis clustering ditentukan pembahasan lebih lanjut unsur ekonomis, terutama yang memiliki kadar signifikan tinggi.

Sampel data primer berbeda dengan sampel data sekunder. Sampel data primer berupa brine yang keluar dari silencer, sehingga telah mengalami pemekatan, baik saat di separator maupun saat keluar dari silencer di PLTP Dieng. Posisi titik pengambilan sampel pada saluran brine yang keluar dari SilencerlAFT (Atmospheric Flash Tank) (Gambar 1). Penanganan sampel pada data sekunder sama dengan data primer, mengacu pada SNI 6989.59 tahun 2008 tentang Air dan air limbah. Sampel dari tiap lokasi disimpan dalam dua jerigen, masing-masing $500 \mathrm{ml}$. Sampel untuk analisis kation sebelum disimpan ke dalam jerigen dilakukan pengawetan dengan mengimbuhkan $\mathrm{HNO}_{3}$ $0,1 \mathrm{~N}$ hingga diperoleh $\mathrm{pH} 2$ (Gambar 2) dengan tujuan menghambat aktivitas mikro organisme serta mengurangi penguapan 
gas dan bahan organik, mulai dari lokasi pengambilan sampel sampai analisis di laboratorium (Nicholson, 1993). Sampel dianalisis kandungan kimianya meliputi $\mathrm{SiO}_{2}, \mathrm{Mg}, \mathrm{Na}, \mathrm{K}, \mathrm{Li}, \mathrm{As}, \mathrm{B}, \mathrm{F}, \mathrm{Cu}, \mathrm{Pb}, \mathrm{Zn}$, dan $\mathrm{Mn}$. Analisis kation ( $\mathrm{Si}, \mathrm{Al}, \mathrm{Fe}, \mathrm{Li}, \mathrm{Na}$, $\mathrm{K}$, dan $\mathrm{Mg}$ ) menggunakan metode AAS; sedangkan analisis anion menggunakan metode lon Cromatography $\left(\mathrm{F}, \mathrm{Cl}, \mathrm{SO}_{4}\right)$, titrimetri $\left(\mathrm{HCO}_{3}\right)$, dan spektrofotometri $\left(\mathrm{NH}_{3}\right)$.

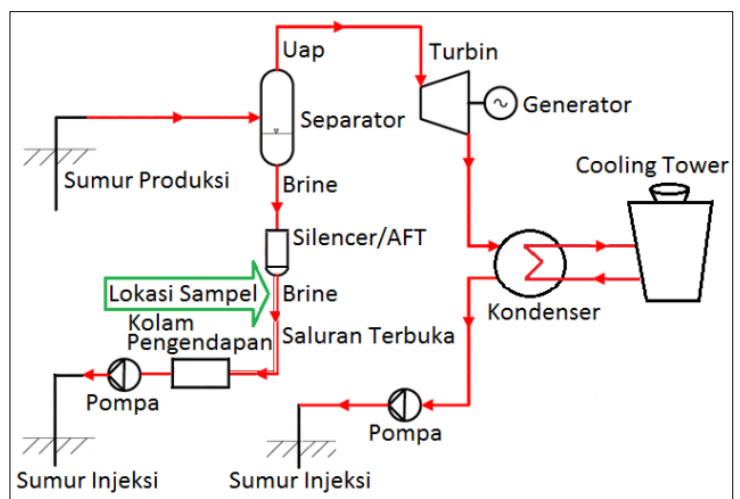

Gambar 1. Diagram alir PLTP Dieng dan titik lokasi pengambilan sampel brine.
Kegiatan pengambilan sampel brine di lingkungan PLTP, PT. Geo Dipa Energi Unit Dieng dilaksanakan pada tanggal 13 Juni 2019. Pengambilan sampel dilakukan di empat lokasi, yaitu pada saluran terbuka di lingkungan cluster sumur (well pad) 30, 31, 7B, dan 28A (Gambar 3). Pengukuran debit brine dilakukan di titik lokasi pengambilan sampel. Mengingat kondisi PLTP dinamis, sebanyak lima sumur sedang dilakukan program workover, untuk meningkatkan produksi total mass flow, maka status data dari hasil penelitian di PLTP Dieng, merepresentasikan kondisi pada saat pengambilan sampel.

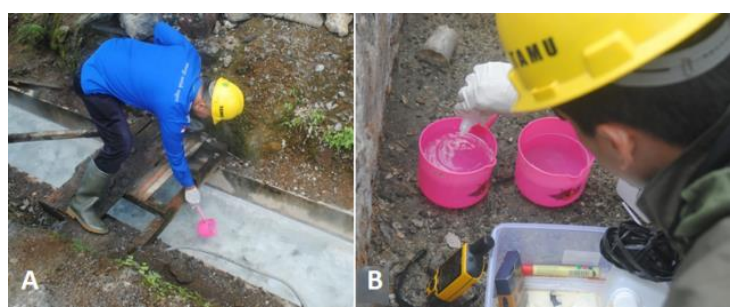

Gambar 2. A. Pengambilan sampel brine. $\mathrm{B}$. Pengawetan sampel brine untuk analisis kation, dengan mengimbuhkan $\mathrm{HNO}_{3} 0,1 \mathrm{~N}$ sampai diperoleh $\mathrm{pH} 2$.

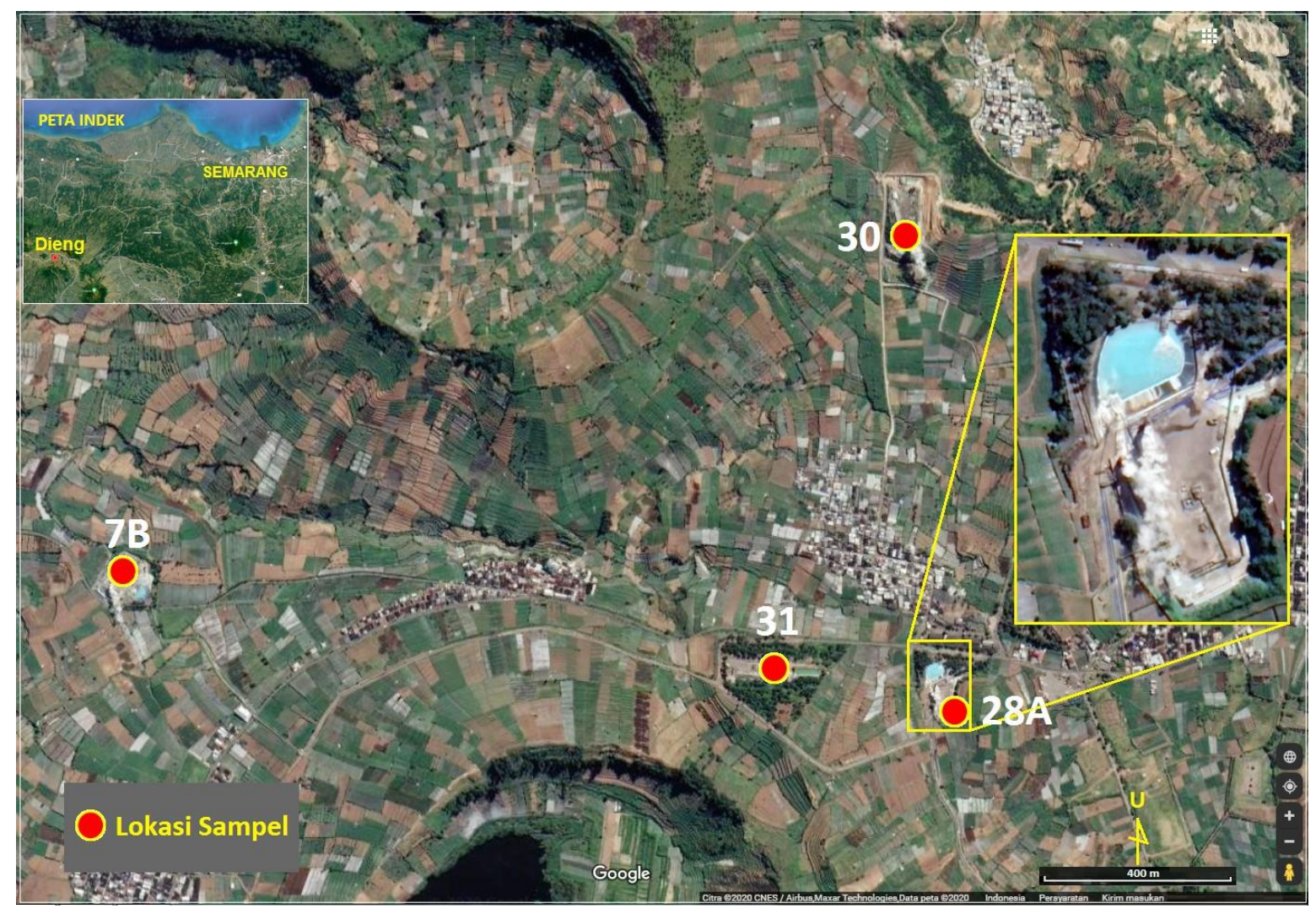

Gambar 3. Daerah Panas Bumi Dieng dan lokasi pengambilan sampel brine. 


\section{MAKALAH ILMIAH}

\section{HASIL DAN PEMBAHASAN}

\section{Hasil Analisis Mata Air Panas}

Pada saat survei atau eksplorasi panas bumi selalu dilakukan analisis kimia kandungan unsur mata air panas. Data hasil analisis kimia pada penelitian ini diperoleh dari berbagai pustaka, terutama dari Badan Geologi, Bandung. Data kandungan unsur dan parameter lainnya dari 256 lokasi mata air panas, seluruh Indonesia, dianalisis statistik secara multivariat dan univariat (Tabel 1). Berdasarkan hasil analisis clustering menggunakan dendogram antara parameter $\mathrm{SiO}_{2}, \mathrm{Al}, \mathrm{Fe}, \mathrm{Ca}, \mathrm{Mg}, \mathrm{Na}, \mathrm{K}, \mathrm{Li}$, As, $\mathrm{NH}_{4}, \mathrm{~B}, \mathrm{~F}, \mathrm{Cl}, \mathrm{SO}_{4}, \mathrm{HCO}_{3}$, didapatkan empat kelompok unsur, dengan batas nilai signifikan $>0,19$, terdiri dari kelompok $\mathrm{SiO}_{2}$ - F, kelompok Al-Fe-SO ${ }_{4}$, kelompok Ca$\mathrm{Mg}-\mathrm{Cl}-\mathrm{Na}-\mathrm{K}$, serta kelompok $\mathrm{Li}-\mathrm{B}-\mathrm{HCO}_{3}$ (Gambar 4). Sedangkan berdasarkan matrik korelasi diperoleh kelompok $\mathrm{Cl}-\mathrm{Na}$ Ca-Mg-K-Li-B, yang menurut klasifikasi Sugiyono (2206) Cl-Na-Ca-Mg-K berkorelasi sangat kuat $(r>0,8)$, antara Mg-K-Li-B berkorelasi kuat $(r>0,6)$. Kelompok Al-Fe-SO ${ }_{4}$ berkorelasi sangat kuat $(r>0,8)$ (Tabel 2).
Kelompok korelasi unsur tersebut dapat menjadi acuan dalam analisis univariat. Peninggian salah satu unsur dalam satu kelompok dapat mengindikasikan peninggian kandungan unsur yang lainnya dalam kelompok asosiasi yang sama. Hal ini apabila salah satu unsur ekonomi diusahakan, unsur yang berasosiasi akan dapat menjadi produk sampingan, demikian juga sebaliknya apabila unsur asosiasinya tidak menjadi produk sampingan akan berpotensi sebagai unsur pengotor saat proses pengolahan dan permurniannya.

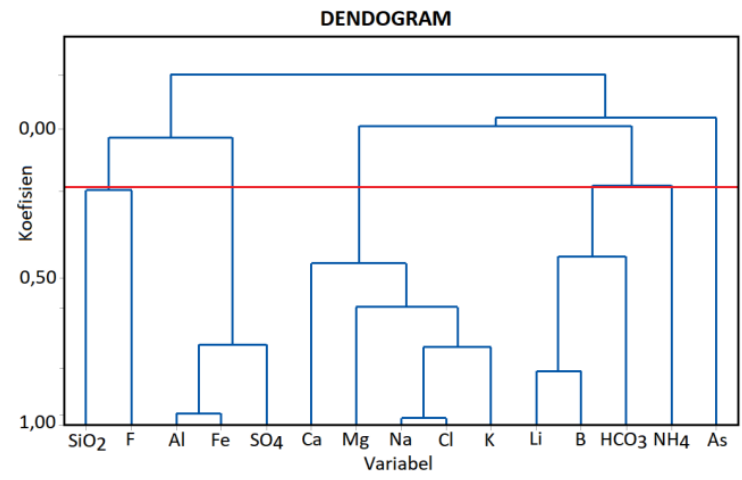

Gambar 4. Dendogram dari hasil analisis kelompok, $\mathrm{n}=256$, nilai $>0,19$ signifikan, data dari lokasi lapangan panas bumi Indonesia.

Tabel 1. Rangkuman statistik data hasil analisis kimia, suhu, $\mathrm{pH}$, dan EC dari 256 lokasi mata air panas Indonesia

\begin{tabular}{lrrrr}
\hline & Minimum $(\mathbf{m g} / \mathbf{l})$ & Maksimum $(\mathbf{m g} / \mathbf{l})$ & Rata-rata $(\mathbf{m g} / \mathbf{l})$ & Standar Deviasi \\
\hline Suhu $\left({ }^{\circ} \mathrm{C}\right)$ & 23,6 & 127,0 & 55,22 & 20,75 \\
\hline $\mathrm{EC}$ & 52 & 47800 & 2605,20 & 4514,29 \\
\hline $\mathrm{pH}$ & 0,45 & 10,4 & 7,23 & 1,21 \\
\hline $\mathrm{SiO}$ & 2,33 & 1254,0 & 109,25 & 105,67 \\
\hline $\mathrm{Al}$ & 0,006 & 376,0 & 2,612 & 25,59 \\
\hline $\mathrm{Fe}$ & 0,006 & 242,0 & 1,93 & 15,97 \\
\hline $\mathrm{Ca}$ & 0,006 & 1260,0 & 84,789 & 148,77 \\
\hline $\mathrm{Mg}$ & 0,006 & 776,7 & 26,99 & 76,28 \\
\hline $\mathrm{Na}$ & 0,80 & 8119,0 & 489,08 & 939,46 \\
\hline $\mathrm{K}$ & 0,02 & 320,4 & 32,85 & 50,73 \\
\hline $\mathrm{Li}$ & 0,01 & 12,5 & 1,24 & 2,25 \\
\hline $\mathrm{As}$ & 0,05 & 331,6 & 1,90 & 20,73 \\
\hline $\mathrm{NH}$ & 0,006 & 26,3 & 2,04 & 3,67 \\
\hline $\mathrm{B}$ & 0,08 & 121,6 & 9,63 & 16,74 \\
\hline $\mathrm{F}$ & 0,02 & 5,1 & 1,50 & 1,18 \\
\hline $\mathrm{Cl}$ & 0,98 & 13660,4 & 649,38 & 1670,97 \\
\hline $\mathrm{SO}_{4}$ & 0,60 & 5094,4 & 211,09 & 460,48 \\
\hline $\mathrm{HCO}_{3}$ & 4,90 & 2105,4 & 394,28 & 397,12 \\
\hline
\end{tabular}


Hasil analisis kandungan unsur dari 256 lokasi mata air, litium pada rentang nilai 0,01-12,50 $\mathrm{mg} / \mathrm{tr}$, dengan rata-rata 1,24 $\mathrm{mg} / \mathrm{tr}$ (Tabel 1). Terdapat enam lokasi mempunyai kandungan Li 6,2-12,5 mg/ltr, sembilan lokasi mempunyai kandungan $\mathrm{Li}$ 2,0 - 6,0 mg/ltr (Gambar 5). Kandungan Li tertinggi dari mata air panas di Lapangan Panas Bumi Lawu sebesar $12,5 \mathrm{mg} / \mathrm{ltr}$ dengan kandungan $\mathrm{K} 184,60 \mathrm{mg} / \mathrm{ltr}$, B $121,64 \mathrm{mg} / \mathrm{ltr}$, dan kandungan $\mathrm{SiO}_{2} 128,65$ $\mathrm{mg} /$ ltr. Lokasi kandungan Li tinggi dari mata air panas terdapat di daerah Boalemo, Bittuang, Lembong, Poso, dan Bukit Kili di Sulawesi, serta Sumani di Sumatera. Dari beberapa lokasi tersebut, keterdapatan peninggian kandungan litium dijumpai baik di lapangan panas bumi non-vulkanik maupun vulkanik (Tabel 3) dengan tipe fluida khlorida.

Hasil kajian panas bumi non-vulkanik daerah Sulawesi bagian tengah, oleh Mulyadi dkk. (2010) menyebutkan bahwa reservoir panas bumi cenderung berada pada kedalaman kurang dari 1000 meter. Dangkalnya reservoir panas bumi di Sulawesi bagian tengah, kemungkinan mempengaruhi tipe dan kandungan unsur fluida di daerah tersebut. Sedangkan reservoir pada lapangan panas bumi vulkanik umumnya mempunyai kedalaman besar, sekitar 1,5 km (Sukhyar dkk., 2014), sehingga komposisi fluida pada mata air panas lebih berpotensi dipengaruhi oleh air meteorik.

Tabel 2. Matrik korelasi data hasil analisis kandungan unsur 256 lokasi mata air panas di Indonesia

\begin{tabular}{|c|c|c|c|c|c|c|c|c|c|c|c|c|c|c|c|}
\hline & $\mathrm{iO}_{2}$ & Al & $\mathrm{Fe}$ & $\mathrm{Ca}$ & $\mathbf{M g}$ & $\mathrm{Na}$ & $K$ & $\mathrm{Li}$ & As & $\mathrm{NH}_{4}$ & B & $F$ & $\mathrm{Cl}$ & $\mathrm{SO}_{4}$ & $\mathrm{HCO}_{3}$ \\
\hline $\mathrm{SiO}_{2}$ & 1 & 311 & 224 & 020 & 0,022 & 0,041 & 152 & 0,184 &, 039 & 089 & 178 & 198 &, 040 & 0,194 &, 107 \\
\hline Al & 311 & 1 & 957 & $-0,006$ & 0,058 & 031 & 257 & 0,012 &, 017 & 131 & 105 & 044 & 153 & 0,725 & 086 \\
\hline $\mathbf{F}$ & 24 & 0,957 & 1 & 11 & 269 & 0,045 & 87 & 32 & 4 & & 24 & 32 & 72 & 43 & \\
\hline $\mathrm{Ca}$ & 20 & 06 & 11 & I & דטדו, & 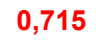 & 47 & 30 & & & & & & & \\
\hline Mg & 2 & 0,058 & 9 & 4 & . & 24 & 95 & 20 & 23 & 99 & 39 & 78 & 756 & 12 & 5 \\
\hline $\mathrm{Na}$ & 0,041 & 0,031 & 0,045 & 0,715 & 0,724 & 1 & 0,736 & 0,306 & 0,073 & 0,108 & 349 & $-0,117$ & 0,975 & 0,339 & 0,205 \\
\hline$K$ & 0,152 & 0,257 & 0,287 & 0,447 & 0,595 & 736 & 1 & 0,543 & 0,055 & 0,119 & 0,519 & $-0,047$ & 0,735 & 0,454 & 0,367 \\
\hline Li & 0,184 & 0,012 & 0,032 & 0,130 & $-0,020$ & 0,306 & 543 & 1 &, 213 & 0,183 & 0,816 & 0,059 & 0,233 & 0,071 & ,423 \\
\hline As & 39 & 017 & 0,014 & 27 & $-0,023$ & 73 & 55 & 0,213 & 1 & $-0,021$ & 286 & $-0,055$ & 062 & 038 & 48 \\
\hline $\mathrm{NH}_{4}$ & 0,089 & 131 & 0,134 & 010 & $-0,009$ & 08 & 19 & 0,183 & $-0,021$ & 1 & 281 & .025 & 0,068 & 0,120 & 261 \\
\hline B & 0,178 & 0,105 & 0,124 &, 185 & 0,039 & 349 & 0,519 & 0,816 & 0,286 & 0,281 & 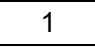 & $-0,058$ & 0,277 & 0,207 & 0 \\
\hline $\mathbf{F}$ & 0,198 & 0,044 & 0,032 & $-0,133$ & $-0,178$ & $-0,117$ & $-0,047$ & 0,059 & $-0,055$ & 0,025 & $-0,058$ & 1 & $-0,114$ & 0,018 & $-0,193$ \\
\hline $\mathrm{Cl}$ & 0,040 & 0,153 & 0,172 & 0,756 & 0,756 & 0,975 & 0,735 & 0,233 & 0,062 & 0,068 & 277 & $-0,114$ & 1 & 0,418 & 0,070 \\
\hline $\mathrm{SO}_{4}$ & 0,194 & 0,725 & 0,743 & 0,292 & 0,412 & 0,339 & 0,454 & 0,071 & 0,038 & 0,120 & 0,207 & 0,018 & 0,418 & 1 & $-0,080$ \\
\hline $\mathrm{HCO}_{3}$ & 0,107 & $-0,086$ & $-0,063$ & 0,059 & 0,085 & 0,205 & 0,367 & 0,423 & $-0,048$ & 0,261 & 0,460 & $-0,193$ & 0,070 & $-0,080$ & 1 \\
\hline
\end{tabular}

Tabel 3. Mata air panas dengan kandungan litium tinggi

\begin{tabular}{llcc}
\hline \multicolumn{1}{c}{ Lokasi Daerah Panas Bumi } & Tipe Panas Bumi & $\begin{array}{c}\text { Kandungan Litium } \\
\text { mg/l }\end{array}$ & $\begin{array}{c}\text { Nama Mata Air } \\
\text { Panas }\end{array}$ \\
\hline $\begin{array}{l}\text { Lawu, Jawa Tengah } \\
\text { (Kusnadi dkk., 2009) }\end{array}$ & Vulkanik & 12,50 & Tipe Fluida \\
\hline $\begin{array}{l}\text { Sumani, Sumatera } \\
\text { (Kusnadi, dkk., 2011) }\end{array}$ & Vulkanik & 10,1 & Karambia \\
\hline $\begin{array}{l}\text { Limbong } \\
\text { (Sundoro, 2009) }\end{array}$ & Non-vulkanik & 10,10 & Lawi \\
\hline $\begin{array}{l}\text { Bituang } \\
\text { (Kusnadi, dkk. 2009) }\end{array}$ & Khlorida \\
\hline $\begin{array}{l}\text { Boalemo } \\
\text { (Setiawan, 2012) }\end{array}$ & Non-vulkanik & 7,9 & Khlorida \\
\hline $\begin{array}{l}\text { Poso } \\
\text { (Dahlan, dkk., 2011) }\end{array}$ & Non-vulkanik & 8,0 & Kanandede II \\
\hline $\begin{array}{l}\text { Seram } \\
\text { (Sulaemanda }\end{array}$ \\
\hline
\end{tabular}




\section{MAKALAH ILMIAH}

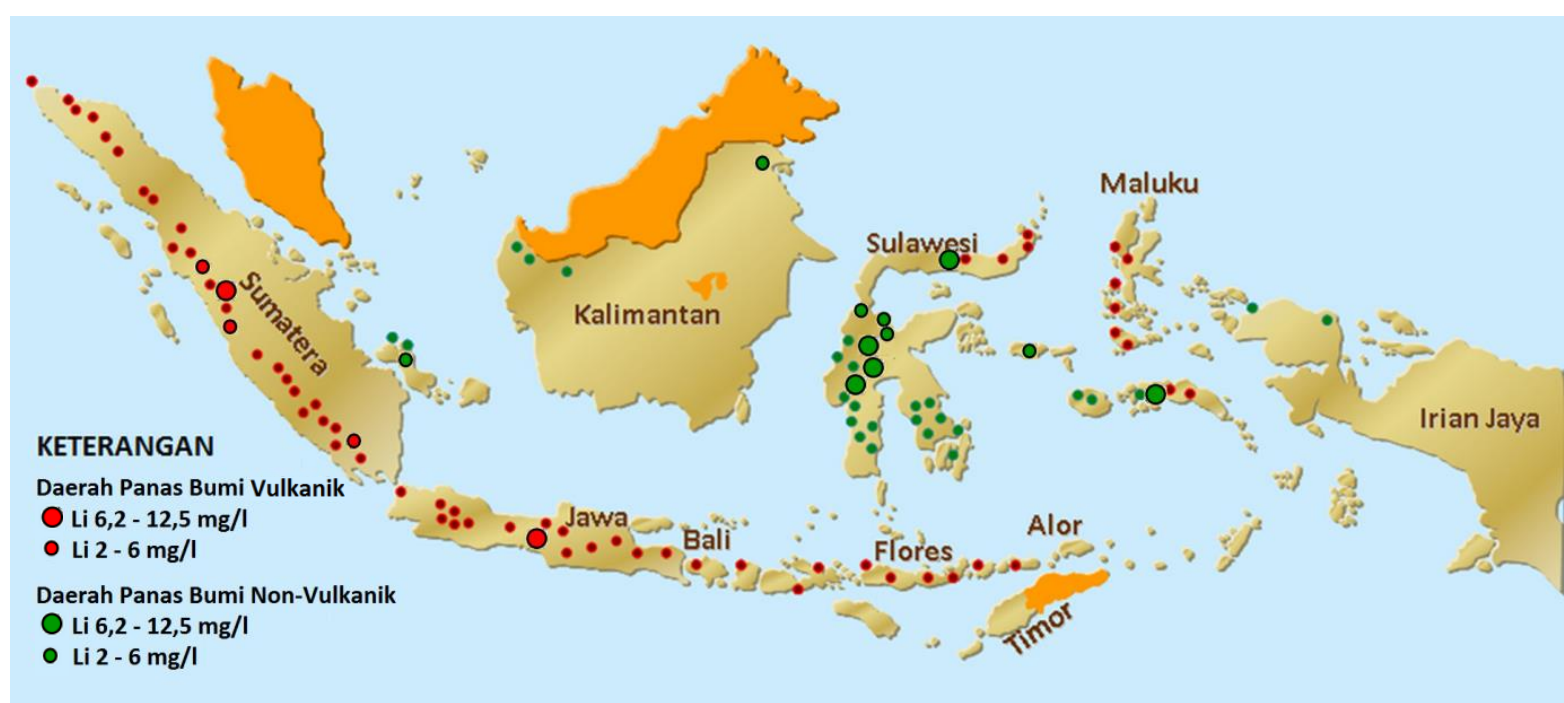

Gambar 5. Peta lokasi daerah panas bumi (Sukhyar, dkk., 2014) dan kandungan Li tinggi pada mata air panas.

Nilai tinggi dijumpai pada daerah panas bumi vulkanik maupun non-vulkanik

Hasil Analisis Fluida PLTP Dieng

Daerah Panas Bumi Dieng berada di Banjarnegara, Jawa Tengah, mempunyai potensi $780 \mathrm{MW}$, dengan kapasitas yang telah terpasang pada PLTP PT Geo Dipa Unit Dieng, 60 MW (Sukhyar dkk., 2014). Pada operasi produksi menghadapi kendala dengan sangat tingginya kandungan silika pada fluida. Namun demikian, dengan kondisi tersebut memberikan peluang untuk dimanfaatkannya kandungan unsur terlarut pada fluida yang diproduksi.

PLTP beroperasi secara komersial mulai tahun 2002, mempunyai temperatur reservoir tinggi, $262^{\circ} \mathrm{C}-330^{\circ} \mathrm{C}$, tipe liquiddominated, kedalaman reservoir pada rentang kedalaman 1.400 dan $1.700 \mathrm{~m}$ (Sirait dkk., 2015). Data unsur ekonomis dari PLTP Dieng berasal dari air panas terproduksi, berupa brine tersisa yang dialirkan menuju kolam pengendapan sebelum diinjeksikan kembali ke dalam bumi. Pengukuran debit fluida dilakukan saat pengambilan sampel. Pengambilan sampel pada empat lokasi, yaitu brine yang berasal dari silencer di lokasi well pad 30, 7B, 31, dan 28A. Pada lokasi 31, mempunyai laju alir brine yang sangat rendah $1,49 \mathrm{~m}^{3} / \mathrm{jam}$, sehingga dari aspek jumlah fluida terlalu sedikit untuk diolah kandungan unsur ekonominya.
Sebagaimana mekanisme yang berlangsung pada sistem operasi produksi pembangkit listrik tenaga panas bumi, adanya proses pressure drop massa fluida, menyebabkan sebagian fasa cair terubah menjadi uap. Pada PLTP Dieng, pressure drop terjadi pada separator dan silencer. Pada separator proses pemisahan fasa cair dan fasa uap, berfungsi untuk memroduksi uap untuk membangkitkan turbin. Proporsi fasa cair (brine) yang masih tersisa dari separator (Tabel 4 dan Gambar 6) dikirim kembali ke dalam reservoir untuk menjaga kelangsungan umur PLTP. Sedangkan pembentukan uap pada silencer akibat brine tersisa dari separator, temperatur masih tinggi, mengalir melewati silencer menuju udara terbuka, sehingga sebagian fasa cair terubah menjadi uap (Gambar 7). Oleh sebab itu dengan berkurangnya fasa cair, menghasilkan brine tersisa dengan tingkat kepekatan meningkat. Lokasi pengambilan sampel pada saluran terbuka setelah brine keluar dari silencer dengan pertimbangan, brine tersisa semakin pekat serta apabila unsur ekonomi yang terkandung pada brine dimanfaatkan, tidak mengganggu sistem operasi produksi pembangkit.

Hasil analisis laboratorium kandungan TDS dari brine 39.882 - 66.936 mg/l (Tabel 4). Sebagai pembanding, sesuai dengan 
Permenkes Nomor 492 tahun 2010 tentang Persyaratan Kualitas Air Minum, dan SNI 3553-2015 tentang Air Mineral, standar TDS maksimum untuk air minum 500 mg/l. Apabila dibandingkan dengan standar tersebut maka kandungan TDS pada brine sangat tinggi dan tidak layak dialirkan ke lingkungan sekitarnya.

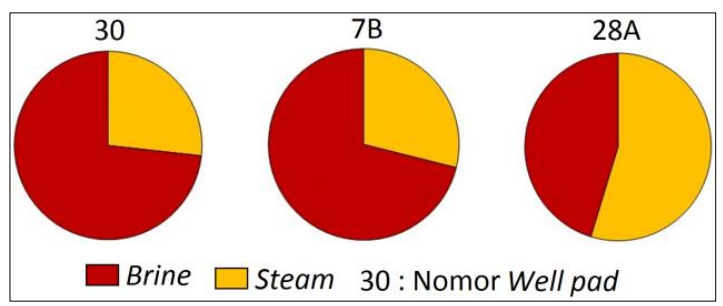

Gambar 6. Proporsi brine dan steam yang dihasilkan dari separator pada tanggal 13 Juni 2019

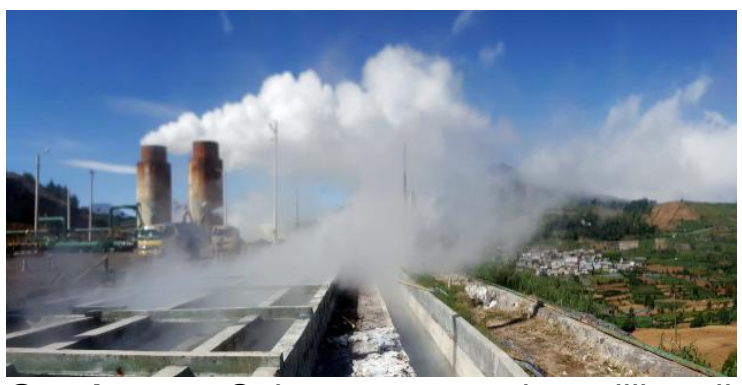

Gambar 7. Saluran pengendap silika di lokasi well pad 30 dengan latar belakang AFT mengeluarkan kepulan uap, menyebabkan brine tersisa semakin pekat.

Unsur terlarut dalam brine mempunyai kadar signifikan diperoleh dari Well pad 30,
7B, dan 28A, dengan kandungan $\mathrm{SiO}_{2}$ 1109,25-1220,90 mg/l, litium 77,31-99,4 $\mathrm{mg} / \mathrm{l}, \mathrm{K} 2532,20-4536,50 \mathrm{mg} / \mathrm{l}$, B 404,16$589,40 \mathrm{mg} / \mathrm{l}$, dan mangan 5,49-15,82 $\mathrm{mg} / \mathrm{l}$ (Tabel 4). Besaran nilai tersebut, apabila mengacu pada hasil asesmen kandungan unsur kimia ekonomis brine geotermal oleh Neupane dan Wendt (2017) yang dilakukan di Amerika Serikat, termasuk kadar sangat tinggi.

Hasil analisis brine PLTP Dieng dari Well pad $30,7 \mathrm{~B}$, dan $28 \mathrm{~A}$ diperoleh kadar $\mathrm{Li}$ 50,11-99,44 mg/l. Besaran nilai tersebut termasuk tinggi, akan tetapi lebih rendah apabila dibandingkan dengan kandungan Li di Salton Sea, Amerika, lokasi telah memroduksi litium dari fluida panas bumi yang mempunyai kadar Li $90-440 \mathrm{mg} / \mathrm{kg}$ (Neupane dan Wendt, 2017) dan B 257 $\mathrm{mg} / \mathrm{kg}$, serta kadar $\mathrm{SiO}_{2} 461 \mathrm{mg} / \mathrm{kg}$ (Mroczek dkk., 2015).

Saat dilakukan penelitian di PLTP Dieng, sedang berlangsung program workover, dengan target lima sumur. Setelah selesainya workover diharapkan akan ada peningkatan mass flow rate dari kelima sumur tersebut. Oleh karena itu debit brine tersisa (Tabel 4) potensial akan menjadi berubah dengan selesainya seluruh program workover. Debit brine tersisa akan meningkat, sehingga potensi dari unsur ekonomi terlarut juga berpotensi meningkat.

Tabel 4. Mass flow rate, dan proporsi antara steam dan brine pada tanggal 13 Juni 2019 (sumber data PT Geo Dipa Enegi Unit Dieng)

\begin{tabular}{|c|c|c|c|}
\hline No Wellpad & $\begin{array}{c}\text { Mass Flow rate pada } \\
\text { Separator } \\
\text { (ton/jam) }\end{array}$ & $\begin{array}{l}\text { Propors } \\
\text { diha }\end{array}$ & $\begin{array}{l}\text { e dan Steam } \\
\text { (ton/jam) }\end{array}$ \\
\hline 30 & 538,10 & Steam: Brine : & $\begin{array}{l}144,00 \\
394,10\end{array}$ \\
\hline $7 b$ & 95,28 & Steam: Brine & $\begin{array}{l}27,54 \\
67,74\end{array}$ \\
\hline 31 & - & Brine & 1,51 \\
\hline 28A & 177,24 & Steam: Brine & $\begin{array}{l}96,95 \\
80,29\end{array}$ \\
\hline
\end{tabular}


Hasil analisis kimia dari 6 lokasi manifestasi mata air panas di daerah Dieng diperoleh kandungan Li 0,01 - 0,88 mg/l, K 21,10 $52,00 \mathrm{mg} / \mathrm{l}, \mathrm{B} 0,32-3,84 \mathrm{mg} / \mathrm{l}, 0,05-0,86$ $\mathrm{mg} / \mathrm{l}, \mathrm{SiO}_{2}$ 38-58,68 mg/l, berdasarkan hasil analisis diagram $\mathrm{Cl}-\mathrm{HCO}_{3}-\mathrm{SO}_{4}$ termasuk tipe bikarbonat (Ramadhan dkk., 2013) mengindikasikan bahwa dominan dipengaruhi oleh air meteorik. Sehingga kandungan $\mathrm{Li}$ pada mata air panas di Daerah Dieng tersebut relatif kecil, bahkan berada di bawah nilai rata-rata, apabila dibandingkan dengan kandungan kimia di lokasi lain di Indonesia. Sementara hasil analisis kandungan unsur $\mathrm{Li}$ dan unsur lainnya yang bernilai ekonomi terlarut pada brine yang keluar dari silencer PLTP Dieng sangat tinggi (Tabel 5). Hal ini mengingat brine yang terproduksi berasal langsung dari zona reservoir, di antara kedalaman 1.400 meter dan 1.700 meter (Sirait, 2015), dan menurut Prasetio dkk., (2010) berdasarkan hasil analisis komposisi isotop gas ${ }^{18} \mathrm{O},{ }^{2} \mathrm{H}$, dan ${ }^{13} \mathrm{C}$ menyimpulkan bahwa fluida panas bumi Dieng berasal dari meteorik yang mengalami interaksi intensif dengan batuan sekitarnya, serta menunjukkan juga adanya kontribusi magmatik. Selain itu tingginya unsur ekonomis terlarut juga akibat proses pemekatan brine yang terjadi di separator dan di silencer. Sehingga kandungan unsur terlarut pada air panas yang diambil dari manifestasi mata air panas jauh berbeda dengan kandungan unsur ekonomi terlarut pada sampel brine yang diambil pada saluran terbuka menuju kolam pengendapan.

\section{KESIMPULAN DAN SARAN}

Diperoleh empat kelompok unsur hasil analisis statistik data dari 256 lokasi mata air panas di Indonesia, kelompok $\mathrm{SiO}_{2}-\mathrm{F}$, kelompok $\mathrm{Al}-\mathrm{Fe}-\mathrm{SO}_{4}$, kelompok $\mathrm{Ca}-\mathrm{Mg}-\mathrm{Cl}-$ $\mathrm{Na}-\mathrm{K}$, serta kelompok $\mathrm{Li}-\mathrm{B}-\mathrm{HCO}_{3}$. Peninggian kandungan litium pada mata air panas dari beberapa daerah panas bumi vulkanik maupun non-vulkanik berupa fluida tipe khlorida atau air formasi.

Fluida dari manifestasi mata air panas di Daerah Dieng termasuk tipe bikarbonat, dominan dipengaruhi oleh air meteorik. Sedangkan fluida terproduksi pada PLTP, dari reservoir tipe meteorik yang mengalami interaksi intensif dengan batuan sekitarnya serta fluida magmatik.

Brine tersisa di PLTP Dieng, mempunyai total debit $457,1 \mathrm{~m}^{3} / \mathrm{jam}$, dengan kandungan kadar tinggi beberapa unsur, litium 77,31-99,4 mg/l, silika 1.109,25 s.d. $1.220,9 \mathrm{mg} / \mathrm{l}$, boron 404,16 s.d. $589,4 \mathrm{mg} / \mathrm{l}$, kalium 2.532,2 s.d. $4536,5 \mathrm{mg} / \mathrm{l}$, dan mangan 5,49 s.d. $15,82 \mathrm{mg} / \mathrm{l}$.

Potensi panas bumi daerah Dieng $780 \mathrm{MW}$, dengan kapasitas telah terpasang $60 \mathrm{MW}$ $(7,7 \%)$, sehingga total potensi unsur yang dapat dikembangkan akan jauh lebih besar apabila seluruh potensi energi panas buminya dikembangkan.

Diperlukan analisis kandungan fluida dengan jumlah unsur yang lebih lengkap agar potensi unsur kimia ekonomis yang lain seperti REE, Au, dan $\mathrm{Ag}$ dapat diketahui.

Tabel 5. Debit aliran, TDS, dan kadar tinggi unsur ekonomis brine PLTP Dieng

\begin{tabular}{|c|c|c|c|c|c|c|c|}
\hline $\begin{array}{l}\text { Nomor } \\
\text { Well pad }\end{array}$ & $\begin{array}{c}\text { Debit } \\
\text { Brine } \\
\text { m³/jam }^{3}\end{array}$ & $\begin{array}{l}\text { TDS } \\
\mathrm{mg} / \mathrm{l}\end{array}$ & $\begin{array}{l}\mathrm{SiO}_{2} \\
\mathrm{mg} / \mathrm{l}\end{array}$ & $\begin{array}{c}\text { B } \\
\mathrm{mg} / \mathrm{l}\end{array}$ & $\begin{array}{l}\mathrm{Mn} \\
\mathrm{mg} / \mathrm{l}\end{array}$ & $\begin{array}{c}\mathbf{K} \\
\mathrm{mg} / \mathrm{l}\end{array}$ & $\begin{array}{c}\mathrm{Li} \\
\mathrm{mg} / \mathrm{l}\end{array}$ \\
\hline 30 & 311,04 & 63.922 & 1201,56 & 455,52 & 10,54 & 4111,20 & 77,31 \\
\hline $7 \mathrm{~B}$ & 66,50 & 39.882 & 1220,90 & 404,16 & 5,49 & 2532,20 & 50,11 \\
\hline $28 \mathrm{~A}$ & 79,56 & 66.936 & 1109,25 & 589,40 & 15,82 & 4536,50 & 99,44 \\
\hline 31 & 1,49 & 16.998 & 556,75 & 791,06 & 1,74 & 1058,20 & 17,22 \\
\hline
\end{tabular}




\section{UCAPAN TERIMAKASIH}

Terimakasih kami ucapkan atas semua bantuannya dalam penelitian ini kepada Manajemen PT Geo Dipa Energi Unit Dieng, Hendra Ardi Kurniawan dari PT Geo Dipa Energi Unit Dieng; Alfia Septiani Syahrul, Khalida Apriani, dan Muhammad Agung Wicaksono dari PEM Akamigas, Mochamad Nur hadi dari PSDMBP.

\section{DAFTAR PUSTAKA}

Bakane, P.A., 2013. Overview of Extraction of Mineral/Metals With The Help of Geothermal Fluid. Proceedings Thirty-Eighth Workshop on Geothermal Reservoir Engineering Stanford University, Stanford, California, February11-13, 2013 SGP-TR-198.

Bloomquist, R.G., 2006. Economic Benefits of Mineral Extraction From Geothermal Brines. Washington State University Extension. Washington.

Bourcier, W.L., Lin, M., Nix, G., 2005. Recovery of Minerals and Metals from Geothermal Fluids. UCRLCONF-215135. 2003 SME Annual Meeting. Cincinnati.

Dahlan, Supeno, Nahar, K., Hendaryanti, L., Suhandjaja, 2011. Survei Pendahuluan Geologi dan Geokimia Daerah Panas Bumi Kabupaten Posos provinsi Sulawesi Tengah. Pusat Sumber Daya Geologi. Bandung.

Glassley, W.E., 2015. Geothermal Energy: Renewable Energy and the Environment. 2nd Edition, Taylor \& Francis Group, LLC, New York.

Hickson, C., \& Coolbaugh, M., 2017. Do Geothermal Systems Play a Role in Lithium Brine Enrichment in Nevada Playas?. GRC Transactions, Vol. 41, 2017. Vancouver.

Kruger, N. 2015. A "Rare" Opportunity. https://www.dmr.nd.gov/ndgs/.

Diunduh 28 September 2015.
Kusnadi, D., Supeno, Kencanawati, L., Hendaryanti, L., 2009. Survei Terpadu Geologi dan Geokimia Daerah Panas Bumi Bituang, Kabupaten Toraja, provinsi Sulawesi Selatan. Pusat Sumber Daya Geologi. Bandung.

Kusnadi, D, Wibowo, A.E.A., Rohani, A., Dinarsih, D., Purwoto, E., Kencanawati, L., 2011. Survei Terpadu Geologi dan Geokimia Daerah Panas Bumi Sumani, Provinsi Sumatera Barat. Pusat Sumber Daya Geologi. Bandung.

Metcalfe, I., 2017. Tectonic evolution of Sundaland. Bulletin of the Geological Society of Malaysia, Volume 63 , June 2017, pp. $27-60$.

Mroczek, E., Climo, M., Li, Y., Evans1, D., Brian Carey., B., and Wei Gao, W., 2015. From Waste to Wealth: Mineral Extraction from Geothermal Brines. Proceedings World Geothermal Congress 2015, Melbourne, Australia, 19-25 April 2015. https://www.researchgate.net/public ation/, diunduh tanggal 29 Juli 2019.

Mroczek, E., Dedual, G., Graham, D., Bacon, L., 2015. Lithium Extraction from Wairakei Geothermal Fluid using Electrodialysis. Proceedings World Geothermal Congress 2015 Melbourne, Australia, 19-25 April 2015.

https://www.researchgate.net/public ation/, diunduh tanggal 29 Juli 2019. Mulyadi, E., Sri Widodo, Yushantarti, A., Wahyuningsih, R., Marpaung, H., dkk., 2010. Kajian Non Vulkanik Panas Bumi di Pulau Sulawesi Bagian Tengah. Pusat Sumber Daya Geologi. Bandung.

Neupane, G., dan Wendt, D.S., 2017. Assessment of Mineral Resources in Geothermal Brines in the US. Proceedings, 42nd Workshop on, Geothermal Reservoir Engineering, Stanford University, Stanford, California,, February 13-15, 2017 SGP-TR 212,

https://www.researchgate.net/public ation/, diunduh tanggal 29 Juli 2019. 


\section{MAKALAH ILMIAH}

Nicholson, K., 1993. Geothermal Fluids, Chemistry and Exploration Techniques. Springer-Verlag, Berlin.

Patterson, M.C.L., 2006. Geotermal BrinesHigh Value Mineral Extraction. Advanced Ceramics Research, 3292 East Hemisphere Loop, Tucson, AZ 85706, USA.

Pohan, M.P., Herman, D.Z., Hutamadi, R. 2008. Penelitian Mineral Ikutan Pada Lapangan Panas Bumi Daerah Dieng, Kabupaten Banjarnegara, Provinsi Jawa Tengah. Pusat Sumber Daya Geologi. Bandung.

Prasetio, R., Abidin1, Z., Yoki Yulizar, Y., 2010. Isotope and Gas Geochemistry of Dieng Geothermal Field, Indonesia. Proceedings World Geothermal Congress 2010 Bali, Indonesia, 25-29 April 2010.

Ramadhan, Y., K. Channel1, K., dan and N. R. Herdianita, N.R., 2013. Hotwater Geochemistry for Interpreting The Condition of Geothermal Reservoir, Dieng Plateau Case, BanjarnegaraWonosobo Regency, Central Java. Indonesian Journal of Geology, Vol. 8 No. 2 Juni 2013.
Sanjuan, B., dan Millot, R., 2009. Bibliographical Review About $\mathrm{Na} / \mathrm{Li}$ Geothermometry and Lithium Isotope Aplied to Worldwide Geothermal Water. BRGM RP-57346-FR, report. Diunduh 22 Desember 2019.

Setiawan, D.I., 2014. Survei Pendahuluan Geologi dan Geokimia Panas Bumi Kabupaten Gorontalo, Boalemo, dan Pohuwato, provinsi Gorontalo. Pusat Sumber Daya Geologi. Bandung.

Sirait, P., Ridwan, R.H., Battistelli, A. 2015. Reservoir Modeling for Development Capacity of Dieng Geothermal Field, Indonesia. Proceedings. Fourtieth Workshop on Geothermal Reservoir Engineering Stanford University, Stanford, California.

Sugiyono, 2006. Statistik untuk Penelitian. CV. Alfabeta. Bandung. Cetakan ke 10.

Sukhyar, R., Gurusinga, C.K., Kasbani, Munandar, A., Dahlan, dkk., 2014. Potensi dan Pengembangan Sumber Daya Panas Bumi di Indonesia. Badan Geologi, Bandung.

Sundoro, H., 2009. Survei Terpadu Daerah Panas Bumi Limbong, Kabupaten Limbong, Provinsi Sulawesi Selatan. Pusat Sumber Daya Geologi. Bandung.

$\begin{array}{ll}\text { Diterima } & : 18 \text { Mei } 2020 \\ \text { Direvisi } & : 24 \text { Agustus } 2020 \\ \text { Disetujui } & : 28 \text { Agustus 2020 }\end{array}$

